\title{
From Trauma Quality Improvement Project to the Geriatric Trauma Institute: Developing an Innovative Care Model for the Coming Storm
}

\author{
${ }^{1}$ Connie M DeLa'O, ${ }^{2}$ Aurelio Rodriguez, ${ }^{3}$ Justin Boer, ${ }^{4}$ Thomas Simunich, ${ }^{5}$ Russell Dumire
}

\begin{abstract}
Background: The US geriatric population is projected to steadily increase to approximately $20 \%$ by 2030 , thereby significantly increasing the burden to trauma services. This study sought to transform the geriatric trauma care model into one more effective, efficient, financially sustainable, and capable of absorbing the anticipated increased demand.
\end{abstract}

Study design: The goals were to improve the geriatric trauma care process - for patient and hospital, detail its evolution, and provide a formative evaluation of the result. A multidisciplinary team, internal and external to the hospital, was assembled including clinical, administrative, and technical staff. Over 18 months, application of Lean Six Sigma tools/concepts produced a novel care model, the Geriatric Trauma Institute (GTI). Retrospectively, formative evaluation was accomplished by comparing pre-GTI data time-matched with that from the first 8 months post-GTI initiation.

Results: The GTI has achieved $100 \%$ involvement of institution orthopedists with $100 \%$ of geriatric trauma admissions being converted to the GTI. Eight months post-GTI, geriatric trauma service admissions increased $26.6 \%$, while non-trauma admissions decreased $78.2 \%$. Out-transfers declined by $28.2 \%$. Patients dispositioned to home increased $26.1 \%$ alongside decreases to rehabilitation (47.2\%), skilled nursing, and transitional care facilities.

Conclusion: Geriatric trauma institute success is evidenced by the quantifiable benefits to patient and hospital. During development, new work processes, tools, and staff training helped boost the utilization of the trauma service regarding

\footnotetext{
${ }^{1}$ Chief Surgical Resident, ${ }^{2}$ Associate Medical Director

${ }^{3}$ Research Intern, ${ }^{4}$ Research Associate, ${ }^{5}$ Medical Director

${ }^{1}$ Department of General Surgery Residency, DLP Conemaugh Memorial Medical Center, Pennsylvania, USA

${ }^{2}$ Department of Trauma Services, DLP Conemaugh Memorial Medical Center, Pennsylvania, USA

${ }^{3,4}$ Office of Research, DLP Conemaugh Memorial Medical Center, Pennsylvania, USA

${ }^{5}$ Department of Trauma, DLP Conemaugh Memorial Medical Center, Pennsylvania, USA
}

Corresponding Author: Connie M DeLa'O, Chief Surgical Resident, Department of General Surgery Residency, DLP Conemaugh Memorial Medical Center, Pennsylvania, USA Phone: 2177663707,e-mail: conniethedoc@gmail.com mailto:cdelao@conemaugh.,org"cdelao@conemaugh.org geriatric trauma care via the novel multidisciplinary approach. The GTI has demonstrated sustained quality improvement in geriatric trauma care maintained through the trauma service performance improvement initiative.

Keywords: Geriatric trauma, Elderly trauma, Cost reduction, Lean six sigma.

How to cite this article: DeLa'O CM, Rodriguez A, Boer J, Simunich T, Dumire R. From Trauma Quality Improvement Project to the Geriatric Trauma Institute: Developing an Innovative Care Model for the Coming Storm. Panam J Trauma Crit Care Emerg Surg 2014;3(3):105-108.

Source of support: Nil

Conflict of interest: None

\section{ABSTRACTO}

Generalidades: La población geriátrica de los Estados Unidos se prevéque aumente de manera constante a aproximadamente el $20 \%$ en 2030 , por lo tanto aumentando la cargaen los servicios de trauma. Este studio buscatransformar el presente modelo del cuidado del trauma geriátrico, en un modelo mas efectivo, eficiente, financier a mente sostenible y capaz de absorber el anticipado aumento de la demanda.

Diseno de Estudio: Los objetivos fueron mejorar el procesodel cuidado del paciente con trauma geriátrico, tanto para el paciente como el hospital, detalles de la evolución y proveer una evaluación formativa de los resultados. Un equipo multi disciplinario interno y externo al hospital fue armado, incluyendo personal clínico, administrativo y técnico. Por mas de 18 meses la aplicación de los conceptos de Lean Six Sigma tools produjo un modelo $n$ ovedoso del manejo del paciente co trauma geriátrico: the Instituto de trauma geriatric. Retrospectivamente a través de una evaluación formativa se comparo la información antes y después de 8 meses después de la implementación del GTI.

Resultados: EI GTI ha logrado el compromiso del 100\% de los ortopedistas de la Institución y con el $100 \%$ de los pacientes con trauma geriatrico sera dmitidos al GTI. Ocho meses después de la instalacióndel GTI, las admisiones del servicio de trauma geriatrico aumentaron $26.6 \%$, mientras que las admisiones no admitidas al Servicio de trauma disminuyo $78.2 \%$. Nuestras transferencias declinaron $28.2 \%$. El envío de pacientes a sus casas aumento $26.1 \%$ al mismo tiempo disminuyeron los pacientes enviados a rehabilitación, instituciones de cuidado de ancianosetc un $47.2 \%$

Conclusion: El éxito del GTI esevidencia dopor los evidentes beneficios del paciente y hospital. Durante su desarrollo, 
nueva sherramientas y procesos, así como entrenamiento de personal, aumentaron la utilizaciónen los servicios de trauma en el cuidado de los pacientes geriátricos, a través de este novedoso proceso multidisciplinario El GTI ha demostrado en una forma de mejoríaso stenida a través del programa de 'performance improvement.'

Palabras claves: Trauma geriátrico, Modelo trauma geriatrico.

\section{INTRODUCTION}

By 2030, the US geriatric population is projected to steadily increase to approximately $20 \%{ }^{1,2}$ Advanced age is a risk factor for adverse outcomes following trauma. The increased burden to trauma services will be significant. An inverse relationship exists with mortality and age. These facts encouraged leading US trauma organizations to establish practice guidelines. ${ }^{3}$ The American College of Surgeons Committee on Trauma has published triage criteria in an attempt to address the need for a more specialized treatment approach in these patients. This study sought to transform the existing geriatric trauma care model into one that is more effective, efficient, financially sustainable, and capable of absorbing the anticipated increased demand.

Geriatric trauma provides many unique challenges to the trauma system. Increasing age is a well documented risk factor for morbidity and mortality in the setting of trauma. ${ }^{4-6}$ There are acute resuscitation and triage issues with under-triage associated with a two-fold increase in mortality and specific high risk injury patterns unique to this patient population. With increasing age there is an associated increase in medical co-morbidities with prevalence increasing with each passing decade. Medications associated with these comorbidities include anticoagulation, beta blockers, diuretics and poly-pharmacy.

Under-triage is common in this population as geriatric patients have deceptive vital signs. Commonly seen is relative hypotension in a patient with baseline hypertension. Additionally, the geriatric patient has diminished physiologic reserve which must be taken into consideration. A retrospective analysis of 10 years by Chang et $\mathrm{al}^{7}$ found the risk for under-triage was significantly higher among those older than 65 years.

The Institute of Medicine ${ }^{8,9}$ has previously cited that industrial engineering innovation should be used to optimize operational efficiency within our healthcare system. One application that was created by Motorola in 1986 that has found adoption within the healthcare sector is Lean Six Sigma Methodology. ${ }^{10}$ Using a blend of Lean Manufacturing and Six Sigma methodologies, Lean Six Sigma seeks to reduce waste and errors with an emphasis on data-driven decision-making to speed process (re-) mapping, constraint identification, and reduce varia- tion. ${ }^{11}$ Utilizing Lean Six Sigma methodology, the study goals were to improve the geriatric trauma care process for patient and hospital, to detail the creation, development, and implementation of the process redesign, and to provide a formative evaluation of the result.

\section{METHODS}

A team comprised of stakeholders, both internal and external to the hospital, was assembled to include clinicians from multiple disciplines and administrative and technical staff. During an 18 month period, Lean Six Sigma tools and concepts of process analysis and redesign were employed to create, develop, implement, and evaluate the resulting novel model of care. Flowing from brainstorming sessions, a SIPOC (suppliers, inputs, process, outputs, and customers) was formulated with the process boundaries being arrival and departure of the geriatric patient from the department of emergency medicine (DEM). In alignment with the institutional strategic plan and a trauma service key performance indicator, the primary goal was to improve the quality (effectiveness and efficiency) of care of the geriatric patient while reducing the length of stay in the DEM. Informally overlaying value stream and time value process maps for context, a root cause analysis was performed using a cause and effect (fishbone) diagram. The identified root causes were assessed for feasibility of implementation; those that were implementable were then ranked using a prioritization matrix. Deployed solutions were iteratively analyzed for desired impact and adjusted as required. Retrospectively, formative evaluation was accomplished by comparing preGTI data time matched with that from the first eight months post-GTI initiation. An alpha criterion was set at 0.05 .

The PreGTI process was extremely fragmented with unstructured processes and poor to non-existent lines of communication. Patients presenting with traumatic injuries were inconsistently admitted to either the primary care service, orthopedic service, or the trauma service, refer to Table 1 . Subsequent consults also varied greatly depending on the admitting service. No protocol was in place for requirement and timing of ancillary service consults during this period.

Table 1: Percent of patients by admit service

\begin{tabular}{|c|c|c|c|c|}
\hline \multirow[b]{3}{*}{ Admit service } & \multicolumn{4}{|c|}{ All Patients } \\
\hline & \multicolumn{2}{|c|}{$\begin{array}{l}\text { Percentage by } \\
\text { admit service }\end{array}$} & \multirow{2}{*}{$\begin{array}{c}\text { Difference } \\
\text { (post- } \\
\text { baseline) }\end{array}$} & \multirow{2}{*}{$\begin{array}{l}\text { Relative } \\
\text { change of } \\
\text { percentages }\end{array}$} \\
\hline & Baseline & Post & & \\
\hline Orthopedic service & $1.2 \%$ & $0.0 \%$ & $-1.2 \%$ & $-100.0 \%$ \\
\hline $\begin{array}{l}\text { Trauma service } \\
\text { (general surgery) }\end{array}$ & $74.9 \%$ & $94.8 \%$ & $19.9 \%$ & $26.6 \%$ \\
\hline Other, nonsurgical & $24.0 \%$ & $5.2 \%$ & $-18.7 \%$ & $-78.2 \%$ \\
\hline
\end{tabular}


Implementation of the Geriatric Trauma Institute included patients being seen within 30 minutes by a trauma team member, immediate consultation of primary care, orthopedics, and physical medicine and rehabilitation as well as physical therapy, occupational therapy, case management and other ancillary service consults within 24 hours. Geriatric trained personnel already employed within the hospital and further trained were utilized in the care of geriatric trauma patients. The development of the GTI created a communication pathway, clear protocols and expectations, and a streamlined process for patient treatment and flow without any infrastructure modifications. In addition, prehospital education, community awareness and outreach programs were implemented as part of the GTI.

\section{RESULTS}

The intense process redesign produced the Geriatric Trauma Institute (GTI). This novel multidisciplinary care model created a horizontal framework of communication, triaging, and consultation under the direction of the GTI. The multidisciplinary approach incorporates expertise from Dietary, Neurosurgery, Occupational Therapy, Orthopedics, Pharmacy, Physical Medicine/Rehabilitation, Primary Care (Physician), Respiratory, Social Services, and Trauma. Within our institution, all of the orthopedic surgeons have agreed that the GTI will be the primary admitting service for their geriatric trauma patients.

Note, the following percentages are relative percent change and $p$-values were produced by testing absolute percentage on time period, pre- and post-GTI. In the 8 months after GTI inception, geriatric trauma service admissions increased by $26.6 \%$, from (253/338) to $(436 / 460)$ patients, with a $78.2 \%$ decrease in non-trauma service admissions (relative percent change), two-tailed p-value $<0.0002$ for each. A $28.2 \%$ decrease in transfers to other hospitals was seen. A discharge destination analysis revealed a $26.1 \%$ increase of patients dispositioned to home (two-tailed p-value $=0.018$ ), a $47.2 \%$ decrease to rehabilitation facilities (two-tailed $\mathrm{p}$-value $<0.0002$ ), and notable decreases to both skilled nursing and transitional care facilities, refer to Table 2.

\section{DISCUSSION}

Carter and Porell ${ }^{12}$ report average cost of healthcare in older trauma patients was $\$ 4,262$ in the month of injury and $\$ 1,092$ in subsequent months post-injury. Both costs represent a significant increase relative to the average monthly preinjury cost of $\$ 681$. This figure is expected to only increase in correlation with increasing healthcare costs in general. In our study, we sought to decrease healthcare costs related to geriatric trauma while demonstrating quantifiable benefits to patients and hospital. Mangram et $\mathrm{a}^{13}$ have previously demonstrated that better outcomes can be obtained by addressing the specific needs of elderly trauma patients using a dedicated unit. We have previously reported success in decreasing length of stay for geriatric patients, which led to reduced hospital charges, following the implementation of the geriatric trauma institute. ${ }^{14}$

Development of multidisciplinary care teams with comprehensive geriatric assessments is a pivotal component of the Geriatric Trauma Institute. The GTI has succeeded as evidenced by the quantifiable benefits to both the patient and the hospital. During the development process, new work processes, tools, and staff training helped to boost the utilization of the trauma service regarding geriatric trauma care via a novel multidisciplinary approach. The GTI has demonstrated sustained and continuous quality improvement in geriatric trauma care. The trauma service maintains the performance gains through the trauma service performance improvement initiative.

We continue to find areas in which we can improve despite the overall process improvements that have been achieved. Length of stay is affected by disposition options in our population. We must continue to expand rehabilitation opportunities for such patients with focus on long term independence in a safe environment. We must continue to strive to reduce the time to the operating room to efficiently get this patient population on the

Table 2: Percent of patients by discharge destination, overall and alive

\begin{tabular}{|c|c|c|c|c|c|c|c|c|}
\hline \multirow[b]{3}{*}{ Discharge destination } & \multicolumn{4}{|c|}{ All patients } & \multicolumn{4}{|c|}{ Alive } \\
\hline & \multicolumn{2}{|c|}{$\begin{array}{c}\text { Percentage by } \\
\text { discharge destination }\end{array}$} & \multirow{2}{*}{$\begin{array}{c}\text { Difference } \\
\text { (post- } \\
\text { baseline) }\end{array}$} & \multirow{2}{*}{$\begin{array}{l}\text { Relative } \\
\text { change of } \\
\text { percentages }\end{array}$} & \multicolumn{2}{|c|}{$\begin{array}{c}\text { Percentage by } \\
\text { discharge destination }\end{array}$} & \multirow{2}{*}{$\begin{array}{c}\text { Difference } \\
\text { (post- } \\
\text { baseline) }\end{array}$} & \multirow{2}{*}{$\begin{array}{l}\text { Relative } \\
\text { change of } \\
\text { percentages }\end{array}$} \\
\hline & Baseline & Post & & & Baseline & Post & & \\
\hline Home & $30.5 \%$ & $39.3 \%$ & $8.9 \%$ & $29.1 \%$ & $32.2 \%$ & $40.6 \%$ & $8.4 \%$ & $26.1 \%$ \\
\hline Rehabilitation center & $21.3 \%$ & $11.5 \%$ & $-9.8 \%$ & $-45.9 \%$ & $22.5 \%$ & $11.9 \%$ & $-10.6 \%$ & $-47.2 \%$ \\
\hline Skilled nursing facility & $25.1 \%$ & $23.0 \%$ & $-2.1 \%$ & $-8.4 \%$ & $26.6 \%$ & $23.8 \%$ & $-2.8 \%$ & $-10.5 \%$ \\
\hline Transitional care unit & $12.4 \%$ & $11.7 \%$ & $-0.7 \%$ & $-5.5 \%$ & $13.1 \%$ & $12.1 \%$ & $-1.0 \%$ & $-7.8 \%$ \\
\hline
\end{tabular}


road to recovery. Additionally, coordination to facilitate quicker dispositions to rehabilitation facilities and skilled nursing facilities continue to be implemented as this has posed an area of bottleneck for patient disposition. On the community level, continued development of injury prevention programs and awareness further improve the overall care of the geriatric population.

\section{REFERENCES}

1. Wan H, Sengupta M, Valkoff VA, DeBarros KA. United States Bureau of the Census. Current Population Reports: Special Studies: Sixty-five plus in America. Washington, DC: Government Printing Office, 2005. p. 23-209.

2. Young JS, Cephas G, Blow O. Outcome and cost of trauma among the elderly: a real-life model of a single-payers reimbursement system. J Trauma 1998;45(4):800-804.

3. Calland J, Ingraham A, Martin N, et al. Evaluation and management of geriatric trauma: An EAST practice management guideline. J Trauma Acute Care Surg 2012;73(5): S345-S350.

4. Moore L, Turgeon A, Sirios M, Lavoie A. Trauma center outcome performance: a comparison of young adults and geriatric patients in an inclusive trauma system. Injury 2012; 43(9):1580-1585.

5. Balla M, Jashuk JL, Willner D, et al. Looking beyond discharge: clinical variables at trauma admission predict long term survival in order severely injured patients. World J Emerg Surg 2014 Jan 23;9(1):10.
6. Keller J, Sciadini M, Sinclair E, O’Toole R. Geriatric trauma: Demographics, injuries, and mortality. J Orthop Trauma 2012;26(9):e161-e165.

7. Chang DC, Bass RR, Cornwell EE, et al. Undertriage of elderly trauma patients to state-designated trauma centers. Arch Surg 2008;143(8):776-781.

8. Institute of Medicine, Committe on the Future of Emergency Care in the United States Health System. Hospital-Based Emergency Care: At the breaking point. Washington, DC National Academy Press; 2006.

9. King DL, Ben-Tovim DI, Bassham J. Redesigning emergency department patient flows: application of Lean Thinking to health care. Emerg Med Australas 2006;18(4):391-397.

10. Frankel HL, Crede WB, Topal JE, et al. Use of corporate Six Sigma performance-improvement strategies to reduce incidence of catheter-related bloodstream infections in a surgical ICU. J Am Coll Surg 2005;201(3):349-358.

11. Brassard M. The Six Sigma Memory Jogger II. Salem, NH: GOAL/QPC/Motorola Inc; 2002. Drickhamer D. Best practices: where lean meets Six Sigma. Industry Week 2002.

12. Carter MW, Porell FW. The effect of sentinel injury on Medicare expenditures over time. J Am Geriatr Soc 2011;59(3): 406-416.

13. Mangram AJ, Mitchell CD, Shifflette VK, et al. Geriatric trauma service: a one-year experience. J Trauma 2012;72(1): 119-122.

14. DeLa'O CM, Kashuk J, Rodriguez A, et al. The geriatric trauma institute: reducing the increasing burden of senior trauma care. Am J Surg 2014 Sep 20;208(6):988-994. 